\title{
Desafios da dupla carreira na formação de futebolistas: olhar sobre a escolaridade
}

Double career challenges in young soccer players: look atschooling

\author{
Renato Henrique Verzani ${ }^{1, *}$ \\ Kauan Galvão Morão ${ }^{1}$ \\ Guilherme Bagni ${ }^{1}$ \\ Afonso Antonio Machado ${ }^{1}$ \\ Adriane Beatriz de Souza Serapião ${ }^{1}$
}

\section{Resumo:}

Objetivo: Analisar o nível de escolaridade de atletas juniores de futebol nos últimos anos e discutir os possíveis reflexos da dupla carreira. Métodos: Foi realizada uma análise dos dados coletados nos anos de 2010, 2013 e 2015, na Copa São Paulo de Futebol Júnior. Resultados: Encontrou-se que os atletas formados no ensino médio aumentaram, partindo de 44,5\% em 2010 para $67,39 \%$ em 2015, bem como que já surgem alguns no ensino superior, mas que devido ao modo como ocorre a estruturação da dupla carreira, é difícil ter alguma certeza quanto a qualidade e aproveitamento dos estudos. Conclusão: o número de atletas que finalizaram o ensino médio aumentou, trazendo sinais de esperança na busca por uma formação mais completa dos jovens, potencializando inclusive a chance de sucesso fora da modalidade para os que não chegam ao esporte profissional, mas que a qualidade destes estudos pode ser contestável, necessitando de maiores discussões neste contexto.

Palavras-chave: desenvolvimento humano, psicologia do esporte, escolaridade, Educação Física, treinamento.

\begin{abstract}
:
Objective:analyze the level of schooling of junior soccer players in recent years and to discuss the possible consequences of the double career.Methods: An analysis of the data collected in the years 2010, 2013 and 2015 was carried out in the São Paulo Junior Football Cup.Results: It was found that high school graduates increased, from $44.5 \%$ in 2010 to $67.39 \%$ in 2015 , but due to the way the double career structuring occurs, it's difficult to have any certainty as to the quality of the studies. Conclusion:the number of athletes who finished high school has increased, showing signs of hope in the search for a more complete formation of the young, increasing even the chance of success out of the modality for those who do not reach the professional sport, but that the quality of these studies can be questionable, requiring further discussion in this context
\end{abstract}

Keywords: human development, sports psychology, schooling, Physical Education, training.
Afiliação dos autores

${ }^{1}$ Universidade Estadual Paulista Júlio de Mesquita Filho, Rio Claro, São Paulo, Brasil.

${ }^{\star}$ Autor correspondente

Universidade Estadual Paulista Júlio de Mesquita Filho, Av. 24 a, 1515, Jardim Bela Vista, CEP: 13506-900, Rio Claro, São Paulo, Brasil. e-mail:renato_verzani@hotmail.com

Conflito de interesses

Os autores declararam não haver conflito de interesses.

Processo de arbitragem

Recebido: 31/10/2017 Aprovado: 30/11/2018 


\section{Introdução}

Por muitos anos, pensar no atleta de futebol e sua formação dentro da modalidade, se restringiu apenas em questões técnicas, táticas e físicas, deixando de lado outros conhecimentos, que podem ser fundamentais na evolução e desenvolvimento dos indivíduos que se propõe a, desde cedo, dedicar sua vida à uma preparação que possivelmente os conduza ao esporte de alto rendimento.

Para Landry ${ }^{1}$, é preciso levar em consideração a importância que 0 esporte possui na formação das pessoas. Seria interessante, então, que as crianças fossem conduzidas para a prática esportiva e, por meio da pluralidade de vivências, percebessem que têm talentos, bem como que estes diferem dos das outras, trazendo assim diversos benefícios, inclusive psicossociais.

Com isso, as contribuições que o esporte traria seriam inúmeras (motoras, cognitivas, educacionais, psicossociais, dentre outras) e favoreceriam as crianças a encontrarem a modalidade que possuem mais afinidade, potencializando as chances de se envolverem de modo mais prazeroso e valioso, para que assim tenham um amplo repertório adquirido e que pode ser importante para o resto da vida, mesmo que não continue no esporte. Caso seja um grande talento, também poderá usá-lo para melhorar a performance.

O termo "talento esportivo" é utilizado para caracterizar sujeitos que apresentam potenciais acima da maioria dos outros de sua faixa etária, em uma modalidade esportiva. Ao ser caracterizado como um talento, o jovem passa a ser alvo de equipes de alto rendimento, que muitas vezes deixam de lado aspectos importantes para o desenvolvimento dos mesmos e atropelam etapas da preparação, podendo trazer prejuízos aos atletas em prol do bem da equipe ${ }^{2}$.

É neste contexto que se torna fundamental analisar o que vem sendo chamado de dupla carreira ("dual carrer"), isto é, um fenômeno que surge na vida de jovens esportistas e que pode ser caracterizado como a dificuldade em conciliar a carreira esportiva e a carreira acadêmica, durante a busca pelo alto rendimento em uma determinada modalidade ${ }^{3}$.

Sendo assim, de acordo com Damo ${ }^{4}$, na formação de um atleta profissional, são necessárias no mínimo 5000 horas de treinamentos direcionados. Este fato revela que o processo é longo e envolve um compromisso do atleta com a finalidade. Para Souza et al. ${ }^{5}$, o futebol no contexto brasileiro passou a ser visto como um projeto de vida, principalmente refletindo sobre as camadas mais populares, quando acreditam encontrar um jovem com talento para uma carreira esportiva de sucesso.

Contudo, dedicar inteiramente suas vidas às modalidades pode não ser vantajoso quando elas se tornam o único projeto de vida dos jovens, sendo que o esporte acaba tomando o espaço da formação escolar e, caso futuramente ocorra um desvinculo com 0 mesmo, há uma grande dificuldade de reconversão, afinal o que foi vivenciado e aprendido no esporte, não possui muito valor no mercado de trabalho ao término da carreira $^{5}$.

Estes jovens dedicam um tempo considerável de suas vidas em busca de espaço em uma profissão que possui um mercado significativamente competitivo e, além disso, possuidor de poucas vagas com grande potencial de retorno financeiro. O que não podemos perder de vista é que, nesta faixa etária, além de todo este tempo dedicado ao esporte, deveria ocorrer também uma dedicação a Educação Básica, responsável pela possibilidade de sucesso no mercado de trabalho ${ }^{6}$.

Levando em consideração que o capital corporal adquirido durante todo o tempo dedicado a tentativa de sucesso na modalidade dificilmente poderá ser convertido em oportunidades no mercado de trabalho ${ }^{5}$, é possível supor que a grande maioria dos atletas malsucedidos nesta busca pelo esporte profissional, não encontrarão um caminho simples ao abandoná-lo.

Com relação a busca por ascensão econômica, se consultarmos os valores que atletas profissionais recebem no Brasil, temos que $84 \%$ recebiam salários de até $R \$ 1000,00$ e apenas 3\% acima de $\mathrm{R} \$ 9000,00$. Contudo, isto não desmotiva os jovens nesta busca pelo profissionalismo ${ }^{3}$.

Neste cenário, surgem ainda os empresários, que buscam grandes retornos financeiros nas negociações de atletas, exercendo grande influência sobre os jovens, por meio de promessas. Sendo assim, muitas vezes o foco para transferências visando o exterior é aumentado, prejudicando ainda mais as possibilidades educacionais.

Este contexto faz com que fique fácil criar uma "linha de produção" de atletas. Segundo Melo et al. ${ }^{3}$, as agências que têm esta finalidade de exportar atletas atuam de maneira livre, devendo apenas obedecer ao preceito legal de manter as crianças matriculadas na escola básica.

A legislação favorece a autonomia dos atletas, bem como impõe limites nos contratos, que têm permissão para ser oficializados a partir dos 16 anos. Contudo, ocorre um processo de "sedução" dos empresários antes desta idade. Isto acontece por meio do oferecimento de empregos aos pais, de auxílios financeiros e diversas outras estratégias, procurando uma fidelização, mesmo antes de firmar contrato ${ }^{7}$.

A partir disto, os atletas que passam a vislumbrar a carreira esportiva, necessitam dedicar aproximadamente 15 horas por semana aos treinamentos, muitas vezes intensos e desgastantes, o que precisa ser somado ao tempo necessário para escola, de aproximadamente 20 horas semanais ${ }^{3}$. Este fato aponta para uma necessidade de renúncias, inclusive quando pensamos no lazer e na convivência familiar.

Sendo assim, durante as mais de 5 mil horas dedicadas a modalidade durante a formação, é evidente que podem haver prejuízos na questão educacional. Uma realidade dos atletas que vivem distantes das famílias, de acordo com Melo ${ }^{8}$, é um volume maior de reprovações, isto é, os atletas analisados no Rio de Janeiro que viviam em alojamentos apresentavam desempenho escolar abaixo dos que moravam com as famílias.

Ao pensar no acesso escolar, é fundamental atentar-se também ao que está sendo feito na escola pelos atletas, uma vez que existem diversas flexibilizações das normas, principalmente com relação ao fato de que muitas vezes estes atletas as representam em competições escolares, em troca de bolsas $^{3}$. Ainda de acordo com este autor, a escola se torna facilitadora no processo de formação do atleta pelo clube. Muitas vezes, as flexibilizações ocorrem em relação ao horário de chegada, dispensas, remarcações de provas, dentre outras.

Sendo assim, percebe-se a necessidade de olhares mais apurados com relação ao modo como tem ocorrido a formação de atletas no Brasil, levando em consideração o nível de estudo e as possíveis implicações psicológicas. O objetivo, portanto, é analisar o nível de escolaridade de jovens atletas de futebol nos últimos anos e refletir sobre o que vem acontecendo no contexto brasileiro de formação nesta modalidade.

\section{Métodos}

Foi realizada uma análise dos dados coletados nos anos de 2010, 2013 e 2015, na Copa São Paulo de Futebol Júnior, verificando os dados que diziam respeito a idade dos atletas, tempo de prática na modalidade e nível de escolarização.

Foram analisados 416 atletas, sendo que esta amostra apresentava a média de 17,54 $( \pm 0,26)$ anos de idade e 7,86 $( \pm 0,92)$ anos de prática. Nos resultados, houve uma separação por ano destes dados, a fim de encontrar a evolução escolar dos sujeitos selecionados.

Nestes anos, os questionários específicos visavam diferentes objetivos, contudo continham as questões sócio demográficas necessárias para esta análise proposta, criando a possibilidade de observar o panorama referente a escolaridade dos atletas participantes.

\section{Resultados}

A partir da análise dos dados, observa-se um panorama referente as amostras de três anos diferentes na Copa São Paulo, sendo que a média de idade e de tempo de prática se mantiveram próximas, com aproximadamente 17 anos de média de idade nos três anos em questão, enquanto o tempo de prática apresentou média próxima de sete nos anos de 2010 e 2013 e de oito em 2015.

Analisando a figura, é possível observar que a grande maioria dos atletas analisados em todos os anos, estava com o ensino médio completo (EM COM) ou incompleto (EM IN), sendo que devemos levar em consideração que, devido a idade dos atletas, estar com o ensino médio incompleto não quer dizer necessariamente abandono, podendo ser entendido que grande parte dos mesmos ainda está cursando esta etapa. 
Com relação ao número de atletas que está com o ensino médio completo (EM COM), houve um aumento nos últimos anos, mesmo levando em consideração que em 2013 o número de analisados foi maior. Em 2010, 53 atletas (44,5\% da amostra) encontravam-se nesta situação, enquanto em 2013 partiu para $78(49 \%)$ e, por fim, em 2015, chegando a 93 jogadores $(67,39 \%)$.

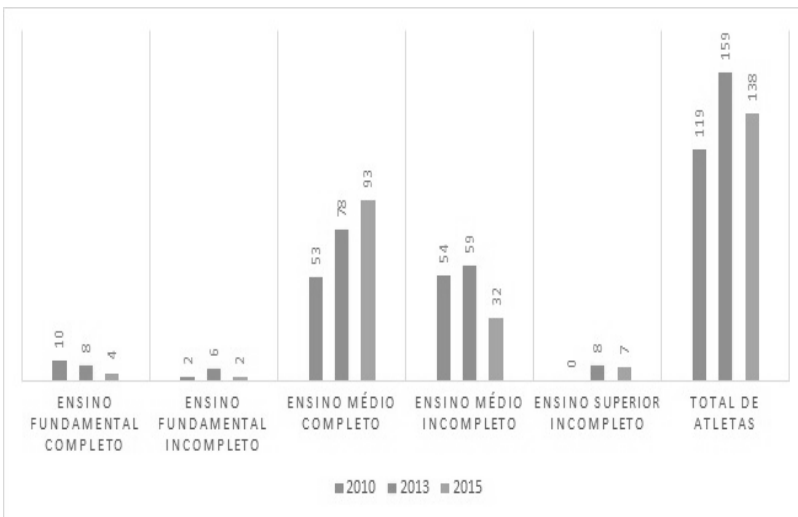

Figura 1. Escolaridade dos atletas

Este dado pode ser bastante valioso ao considerar o que foi apontado por Souza et al. (2008), isto é, que há um risco excessivo quando os jovens dedicam sua vida exclusivamente a preparação para uma modalidade esportiva, deixando a escola de lado, dificultando a reconversão para o mercado de trabalho caso o esporte não se confirme profissão, futuramente.

Outro fato interessante é observar que existem atletas, nas últimas duas edições estudadas, que estão cursando o ensino superior, indicando assim que existe o interesse de alguns por continuar estudando (a primeira edição selecionada contava com idade limite mais baixa, por isso que não existem atletas nesta condição, provavelmente).

Pode-se visualizar que o número de atletas que apresenta ensino fundamental incompleto (EF IN) também diminuiu, bem como o número dos que pararam no ensino fundamental (EF COM), uma vez que aumentaram os envolvidos com o ensino médio.

\section{Discussão}

Temos que ter certo cuidado ao analisar o maior nível de escolaridade dos futebolistas, afinal, de acordo com as contribuições de Rocha et al. ${ }^{7}$, isso não representa a qualidade do ensino que estes estão tendo. Nos centros de formação esportiva, o que fica bastante claro é a liberdade que possuem para definir o tempo de treinamento e a capacitação dos profissionais que estarão envolvidos, além das questões estruturais, etc. $\mathrm{O}$ que os clubes argumentam é que existe uma obrigação para estudar, mas de acordo com $\mathrm{Melo}^{8}$, não existe qualquer acompanhamento dos estudos pelos clubes. Damo ${ }^{4}$ cita o exemplo da França, país no qual existe uma política relacionada à compatibilidade da formação esportiva e a escolarização.

Outro dado interessante é o apontado por Szeremeta et al. ${ }^{9}$, em um estudo envolvendo treinadores brasileiros e portugueses, no qual constatou-se que os clubes brasileiros têm um discurso que não condiz com o que ocorre na prática, isto é, não possuem postura rígida quanto ao desempenho escolar, levando em consideração apenas as chances de lucros. Assim, não há grandes exigências, desde que o desempenho seja alto.

Neste mesmo estudo de Szeremeta et al. ${ }^{9}$, por sua vez, percebe-se a diferença de postura no contexto português, no qual os técnicos afirmam que as notas precisam estar em padrões aceitáveis para que não haja dispensa em treinamentos e competições. Foi citado também que duas notas negativas levavam ao afastamento de treinos e três, das competições. Um dos técnicos salientou que já aconteceu de ficar sem cinco dos titulares e perder rendimento da equipe, mas que houve maior interesse dos atletas na questão educacional, evidenciando as diferenças contextuais.

Sem esta preocupação, percebe-se que grande parte do tempo dos jovens é ocupado com atividades de formação profissional em uma área muito competitiva e com poucas chances reais de bons retornos financeiros, o que deveria ser alterado para valorização da educação básica destes jovens ${ }^{6}$.

Desta forma, somam-se diversos aspectos que contribuem para um desinteresse por parte dos atletas em ter uma educação de qualidade, como o cansaço dos treinamentos, dificuldades para assistir aulas e estudar devido as competições e viagens, o próprio insucesso escolar, desvalorizando assim a importância da escola e supervalorizando o esporte ${ }^{4}$.

Outro fator que pode ser fundamental nesta análise da formação esportiva em detrimento da escolar, é que em profissões que necessitam de formação mais prolongada ou ensino superior, existe a possibilidade de iniciar com 25 anos ou mais, enquanto em esportes como o futebol, a vida profissional se inicia ainda no final da adolescência, dificultando desta forma a possibilidade de reconversão para os que não alcançarem o sucesso esportivo ${ }^{5}$.

Contudo, ao pensar no aumento do nível de escolaridade dos atletas apresentado neste trabalho, é possível fazer algumas observações que justifiquem esta mudança, uma vez que ela pode estar sendo baseada em interesses alimentados por necessidades dos investidores.

Isto ocorre devido a fatores como o apontado por Souza et al. ${ }^{5}$, ou seja, jovens que não tiveram boas oportunidades com relação a educação, moradia adequada ou mesmo uma alimentação saudável, podem apresentar grandes dificuldades de adaptação no cenário europeu, que é um dos principais destinos no país, prejudicando desta forma os lucros dos clubes e empresários.

Sendo assim, podemos apontar uma possível justificativa para este aumento na escolaridade, mesmo levando em consideração as rotinas intensas de treinamentos, devido a liberdade que os formadores possuem com relação a este controle.

A partir disto, precisa-se refletir que mudanças neste quadro são importantes para os atletas, até porque é evidente que grande parte dos que chegam até uma categoria sub-20 não serão aproveitados em alguma equipe profissional. Grossmann e Lames ${ }^{10}$, por exemplo, citam que não chega a $10 \%$ o número de atletas que alcançam o esporte profissional.

Szeremeta et al. ${ }^{3}$ enfatizam que este momento de passagem para o esporte profissional é um dos mais complicados, sendo que grande parte acaba sendo cortado e deixando a modalidade, reforçando a necessidade de ter outros capitais agregados.

Outra diferença contextual apontada por estes autores em relação aos atletas cortados diz respeito a indicação para outras equipes, o que é uma realidade em Portugal e não acontece no Brasil, devido ao medo dos técnicos abalarem sua reputação com indicações de atletas que não agradem, dificultando ainda mais a vida dos jovens esportistas brasileiros.

Quanto ao bem-estar psicológico, pode haver prejuízo na perspectiva que investiga o potencial humano, chamada de bem-estar eudemônico, que apresenta a necessidade do funcionamento correto das potencialidades de um sujeito, como no caso da capacidade de pensar, raciocinar e fazer uso do bom senso ${ }^{11}$

Analisando as questões psicológicas, temos ainda que os atletas muitas vezes apresentam dificuldades para lidar com uma série de questões, que também costumam ser deixadas de lado por quem cuida da preparação dos mesmos, interferindo psicologicamente e afetando o desempenho.

As pressões surgem de todos os lados, seja dos pais, patrocinadores, treinadores, empresários, clubes, dentre outros. Diante disso, muitos não conseguem lidar com as situações e partem para estratégias não adequadas neste enfrentamento de problemas.

Wiethaeuper e Balbinotti ${ }^{12}$ afirmam que os atletas que sofrem pressões podem recorrer a diversas maneiras de manejar as emoções, como drogas, álcool ou até mesmo automutilações, sendo que o controle emocional estaria ligado as ações que na realidade eram autodestrutivas. As pressões externas refletem, então, diretamente nas questões internas do indivíduo.

Percebe-se assim, de acordo com Gregório e Silva ${ }^{13}$, que existem riscos em uma participação esportiva que seja conduzida de modo equivocado relacionados com exigências em aspectos emocionais e psicológicos. Isto se deve ao fato de 
que jovens são envolvidas em um universo de cobrança dignos de adultos, na busca por desempenho, deixando de lado diversos fatores, que podem trazer prejuízos.

Este tipo de situação, bem como a interferência inadequada neste contexto, leva a diversos reflexos, como no caso do excesso de cobranças, da necessidade de resultados excepcionais, do feedback negativo e mesmo de uma organização excessiva, podendo então, como citado por Gomes $^{14}$, promover um direcionamento para 0 abandono esportivo.

Outra suposição que pode ser levantada é que os atletas que possuem escolaridade menor, tendem a usar mais estratégias de enfrentamento de problemas inadequadas. $O$ estudo de Bagni et al. ${ }^{15}$ apontou para uma grande utilização da estratégia de enfrentamento baseada no pensamento fantasioso/ religioso em atletas de futebol de base, sendo que estes estavam em sua grande maioria, no máximo com ensino médio completo.

Já o estudo de Verzani et al. ${ }^{16}$, que avaliou as estratégias de enfrentamento de problemas em atletas universitários, encontrou que esta estratégia é menos utilizada, uma vez que as estratégias baseadas no foco do problema ou no suporte social, que são consideradas como mais adequadas pela literatura, possuem um papel de maior destaque entre o que foi assinalado.

Portanto, podemos sugerir que os reflexos de uma formação inadequada dos atletas podem trazer prejuízos, tanto para a vida dos sujeitos, quanto para a carreira esportiva dos que conseguirem permanecer, profissionalmente.

\section{Conclusão}

Portanto, pode-se concluir que houve alteração no nível de escolaridade de jovens atletas de futebol em formação, visto que a conclusão do ensino médio aumentou, bem como surgiram atletas cursando ensino superior nas duas últimas edições, aumentando a esperança de uma formação adequada neste contexto

Contudo, fica difícil saber se a qualidade deste ensino está correspondendo a este aumento, visto que muitas vezes as escolas, com o apoio dos clubes, fazem diversas concessões a estes atletas/alunos, levando os jovens a priorizar o esporte, tornando este caminho mais atraente.

Desta forma, é essencial que as questões envolvendo a formação tenham um viés mais amplo, pois este momento da vida dos jovens é muito importante para o futuro e não podemos colocar em risco devido a interesses dos clubes e empresários, dificultando a reconversão dos que não derem continuidade à pratica esportiva.

\section{Referências}

1. Landry GL. Benefícios da prática esportiva. In: Sullivan JA, Anderson, SJ (Org.). Cuidados com o jovem atleta: enfoque interdisciplinar na iniciação e no treinamento esportivo. Barueri: Manole, 2004. p 1-8.

2. Lanaro Filho P, Böhme MTS. Detecção, seleção e promoção de talentos esportivos em ginástica rítmica desportiva: Um estudo de revisão. Rev. paul. Educ. Fís 2001; 15(2):154-168.

3. Melo LBS, Soares AJG, Rocha HP. Perfil educacional de atletas em formação no futebol. RevBrasEducFís Esporte 2014; 28(4): 617-628.

4. Damo AS. Do dom à profissão: uma etnografia do futebol de espetáculo a partir da formação de jogadores no Brasil e na França. [Tese de Doutorado - Programa de Pós-Graduação em Antropologia Social]. Porto Alegre (RS): Universidade Federal do Rio Grande do Sul; 2005.

5. Souza CAM, Vaz AF, Bartholo TL, Soares AJG. Difícil reconversão: futebol, projeto e destino em meninos brasileiros. Horiz. Antropol 2008; 14(30):85-111.

6. Soares AJG, Melo LBS, Costa FR, Bartholo TL, Bento JO. Jogadores de futebol no Brasil: mercado, formação de atletas e escola. Rev. Bras. Ciênc. Esporte 2011; 33(4): 905-921.

7. Rocha HPA, Bartholo TL, Melo LBS, Soares AJG. Jovens Esportistas: profissionalização no futebol e a formação na escola. Motriz: rev. educ. fis 2011; 17(2): 252-263

8. Melo LBS. Formação e escolarização de jogadores de futebol no Estado do Rio de Janeiro. [Dissertação - Mestrado em Educação Física] Rio de Janeiro (RJ): Universidade Gama Filho; 2010.

9. Szeremeta TP, Conde JHS, Figueiredo AJB, Gonçalves CEB, Cavichiolli FR. A formação de jovens futebolistas além das quatro linhas: uma análise sob a ótica dos técnicos de Brasil e Portugal. Pensar Prát 2017; 20(1): 112-124.

10. Grossmann B, Lames M. FromTalentto Professional Football - Youthism in German Football. Int J Sports Sci Coach 2015; 10(6): 1103-1113.

11. Comin FS, Santos MA. Avaliação das emoções: considerações sobre o conceito de bem-estar subjetivo e sua utilização na ciência psicológica. In: Bartholomeu D, Montiel JM (Org.). Atualização em avaliação e tratamento das emoções. São Paulo: Vetor, 2013. 21-40.

12. Wiethaeuper D, Balbinotti MAA. Regulação das emoções. In: Bartholomeu D, Montiel JM (Org.). Atualização em avaliação e tratamento das emoções. São Paulo: Vetor, 2013. 485-496.

13. Gregório KM, Silva T. Iniciação esportiva $X$ especialização esportiva precoce: quando iniciar estas práticas? Horizontes2014; 3(2): 49-65.

14. Gomes AR. A iniciação e formação desportiva e o desenvolvimento psicológico de crianças e jovens. In: Machado AA, Gomes AR (Org.) Psicologia do esporte: da escola à competição. Jundiaí: Fontoura, 2011. 19-48

15. Bagni G, Machado AA, Barbosa CG, VerzaniRH, Morão KG. Estratégias de enfrentamento de problemas em jovens atletas: um estudo através do EMEP. Coleç. Pesqui. Educ. Fís. 2013; 12(2): 63-70.

16. Verzani RH, Morão KG, Bagni G, Barbosa CG, Machado AA. Coping e o esporte universitário. Motriz: rev. educ. fis. 2015; 21(2 Suppl 1): s17-s18. 